\title{
High-risk environments for eating foods surplus to requirements: a multilevel analysis of adolescents' non-core food intake in the National Diet and Nutrition Survey (NDNS)
}

\author{
Zoi Toumpakari $^{1, *}$, Kate Tilling ${ }^{2}$, Anne $M$ Haase $^{1}$ and Laura Johnson ${ }^{1}$ \\ ${ }^{1}$ Centre for Exercise, Nutrition and Health Sciences, School for Policy Studies, University of Bristol, 8 Priory Road, \\ Bristol BS8 1TZ, UK: ${ }^{2}$ School of Social and Community Medicine, University of Bristol, Bristol, UK
}

Submitted 1 February 2018: Final revision received 31 August 2018: Accepted 25 September 2018: First published online 8 November 2018

\begin{abstract}
Objective: Interventions to reduce adolescents' non-core food intake (i.e. foods high in fat and sugar) could target specific people or specific environments, but the relative importance of environmental contexts $v$. individual characteristics is unknown.

Design: Cross-sectional.

Setting: Data from $4 \mathrm{~d}$ food diaries in the UK National Diet and Nutrition Survey (NDNS) 2008-2012 were analysed. NDNS food items were classified as 'non-core' based on fat and sugar cut-off points per $100 \mathrm{~g}$ of food. Linear multilevel models investigated associations between 'where' (home, school, etc.) and 'with whom' (parents, friends, etc.) eating contexts and non-core food energy (kcal) per eating occasion (EO), adjusting for variables at the EO (e.g. time of day) and adolescent level (e.g. gender).

Participants: Adolescents ( $n$ 884) aged $11-18$ years.

Results: Only $11 \%$ of variation in non-core energy intake was attributed to differences between adolescents. In adjusted models, non-core food intake was $151 \%$ higher (ratio; 95\% CI) in EO at 'Eateries' $(2 \cdot 51 ; 2 \cdot 14,2 \cdot 95)$ and $88 \%$ higher at 'School' (1.88; 1.65, 2.13) compared with 'Home'. EO with 'Friends' (1.16; CI 1.03, $1 \cdot 31)$ and 'Family \& friends' $(1 \cdot 21 ; 1 \cdot 07,1 \cdot 37)$ contained $16-21 \%$ more non-core food compared with eating 'Alone'. At the individual level, total energy intake and BMI, but not social class, gender or age, were weakly associated with more noncore energy intake.

Conclusions: Regardless of individual characteristics, adolescents' non-core food consumption was higher outside the home, especially at eateries. Targeting specific eating contexts, not individuals, may contribute to more effective public health interventions.
\end{abstract}

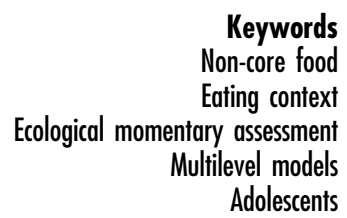

Keywords

Non-core food

Eating context

Adolescents
Poor diets account for $10 \%$ of the global burden of disease $^{(1)}$. Adolescence represents a time when dietary intakes are at their worst ${ }^{(2,3)}$ and a trajectory is set for inadequate dietary intake in adulthood. Interventions to improve diet and reduce the burden of disease are urgently required. In the UK, adolescents' diet is not optimal and according to the most recent National Diet and Nutrition Survey (NDNS), their intakes of saturated fats and added sugars are excessive ${ }^{(4)}$. A few policies in the UK have tried to improve adolescents' food consumption, such as the implementation of school food standards to improve school meals ${ }^{(5)}$. Consumption of energy-dense nutrient-poor foods at this age is an issue of public health concern and comprises one of the key strategies to prevent childhood obesity ${ }^{(6)}$.
Core foods provide the body with all the essential nutrients required for health and should form the basis of everyday diet, whereas non-core or discretionary foods are surplus to requirements and should have limited consumption. In the UK, non-core foods like regular soft drinks, crisps and savoury snacks, chips and potato products, chocolate and biscuits make up $40 \%$ of adolescents' total energy intake $(\mathrm{EI})^{(7)}$, vastly exceeding recommendations ${ }^{(8,9)}$.

Understanding the context of non-core energy consumption, in terms of where and with whom adolescents eat non-core foods, could help identify high-risk environments where interventions can be focused. In descriptive analyses we have shown that a greater proportion of energy eaten in eateries or with friends is non-core, thus 
these contexts may represent high-risk environments for eating surplus to requirements ${ }^{(7)}$. However, these analyses did not consider the interrelationships between characteristics of eating contexts; for example, eating occasions (EO) with parents are more likely to be an evening meal $^{(10)}$. Furthermore, potential confounding by individual adolescent characteristics, such as age, sex or socioeconomic status (SES), could explain associations ${ }^{(11)}$. It is unclear if greater non-core food intake occurs in eateries and with friends because of those physical and social contexts per se or because the type of people who eat in those contexts more often generally eat more noncore foods.

A way to overcome this is the use of ecological momentary assessment (EMA), i.e. collecting real-time information on people's behaviours in natural environments, which has had limited application in nutritional research $^{(12)}$. EMA can be combined with dietary assessment using multiday diet diaries, which offer data on many EO in multiple different contexts for the same person. This will allow associations of specific contexts with non-core food intake to be estimated within-person while holding variation in individual characteristics constant. Multilevel modelling (MLM) can partition variation in the amount of non-core food eaten in an EO to within- and betweenperson sources to explore the relative contribution of the individual characteristics $v$. the environment.

A couple of analyses have explored the association of eating context with food intake by accounting for withinand between-person variation or the use of $\operatorname{EMA}^{(12,13)}$. Both these studies highlighted specific environments that could benefit from the provision of healthier food choices to improve children's and adults' food intake, suggesting similar environmental targets could be identified to reduce adolescents' non-core food consumption, but to our knowledge no studies in adolescents have yet been conducted.

We aimed to determine the independent relationship between specific eating contexts and non-core energy consumption in an EO, by focusing on variation in the characteristics of different EO within adolescents while holding between-adolescent variation constant.

\section{Methods}

\section{Study sample}

Dietary data were used from 884 adolescents aged 11-18 years old from Years 1-4 (2008/09-2011/12) of the UK NDNS rolling programme. Details about the design of NDNS can be found elsewhere ${ }^{(4)}$; relevant details to the current analysis are described below. The NDNS was conducted according to the Declaration of Helsinki and was approved by the Oxfordshire A Research Ethics Committee $^{(4)}$. Data for the present analysis were downloaded from the UK data archive ${ }^{(14)}$.

\section{Dietary data}

Participants completed a $4 \mathrm{~d}$ food diary recording details of all EO including foods and drinks consumed, while a form of EMA was used to collect information on 'where' and 'with whom' the EO occurred. Further description about the dietary assessment can be found elsewhere ${ }^{(15)}$. Foods and food groups ${ }^{(16)}$ were classified as non-core using specific fat and sugar cut-off points per $100 \mathrm{~g}$ of food ${ }^{(17)}$, following a previously used approach ${ }^{(18)}$. A total of twenty food groups containing non-core foods was determined. Further information about the allocation of foods to noncore can be found elsewhere ${ }^{(7)}$. Raw data represented one food item consumed by one adolescent within one EO in each row. EO were defined as all food and drink items consumed together by the same person, on the same day, at the same time. Total non-core EI (kcal) per EO was the sum of energy from all non-core foods and drinks reported.

\section{Definition of eating context}

NDNS used EMA to collect real-time information on where and with whom food consumption occurred. Thirty six locations of EO were collapsed into seven categories ('Home'; 'Friend's/relative's house'; 'School'; 'Eateries', such as restaurants, cafés and fast-food places, 'On the go'; 'Activity/other places'; 'Work') and nineteen 'with whom' categories were collapsed into six groups ('Alone'; 'Parents/carers'; 'Parents \& siblings'; 'Family \& friends'; 'Friends'; 'Not specified') for analysis ${ }^{(7)}$. For the 'where' and 'with whom' categories 'Home' and 'Alone' were the reference groups, respectively.

\section{Potential confounders}

A review of the literature and the availability of data in the survey informed the selection of potential confounders, which included: (i) time (hours) of each EO; (ii) day of each EO (either weekday (Monday-Friday) or weekend day (Saturday-Sunday)); (iii) television watching; (iv) sex; (v) age (years); (vi) BMI $\left(\mathrm{kg} / \mathrm{m}^{2}\right.$ ), computed from measured weight and height and standardised for age and sex using the 1990 British Growth Reference ${ }^{(19)}$. BMI categories (i.e. underweight, normal weight, overweight and obese, based on International Obesity Task Force criteria) were also created and were used in interaction models; (vii) adolescent SES indicated by parental occupation (high, intermediate or low (reference category)) based on the National Statistics Socio-Economic Classification (NSSEC) ${ }^{(20)}$; and (viii) adolescents' average total daily EI (per $4184 \mathrm{~kJ}(1000 \mathrm{kcal}) / \mathrm{d})$.

\section{Data analysis}

The frequency and percentage of all EO and characteristics of EO in specific 'where' and 'with whom' eating contexts are reported at the survey level. Total and noncore EO per day consumed by adolescents overall and in 
specific contexts are described using means and standard deviations. Individual characteristics of adolescents reporting EO overall and in specific contexts are described using frequencies and percentages (for categorical variables) and means and standard deviations (for continuous variables). Pearson $\chi^{2}$ tests were used to examine simple associations between eating contexts and categorical characteristics of EO or adolescents. Differences between eating contexts and continuous variables were examined using Kruskal-Wallis tests for non-normal and ANOVA for normally distributed variables.

\section{Multilevel modelling}

$\mathrm{MLM}^{(21)}$ investigated the relationship of eating contexts with non-core energy consumption. Level 1 variation was in characteristics of EO (where, with whom, time and day of the week of each EO and television watching) and level 2 variation was in characteristics of adolescents (age, sex, SES, BMI and total EI). EO are nested within adolescents; hence MLM allowed us to explore whether non-core EI varies within and between adolescents, as well as factors that explain this variability. Non-core energy (kcal) per EO was not normally distributed, owing to non-consumption of non-core foods in $31 \%$ of EO, and was logged to approximate the normal distribution.

A series of models were run: Model 1 was the null intercept model, which included just the adolescent identifier in the random part of the model, to explore the extent to which differences in non-core EI were bigger between adolescents $v$. within adolescents. Models $1 \cdot 1$ to 1.9 are random-intercept univariable models, where each model included the adolescent identifier and an additional single explanatory variable from either the EO or adolescent level entered separately in their own model. These models examined the individual effect of each EO-related variable on non-core energy. Model 2 is a randomintercept model and included all explanatory variables at the EO level from Models 1.1 to 1.4 simultaneously to explore the independent effect of each eating context on non-core energy consumption, accounting for time of day and day of the week. Model 3 was Model 2 plus all adolescent-related variables from Models 1.5-1.9 to explore the independent effect of each eating context on non-core energy consumption accounting for time of day, day of the week and between-adolescent differences (i.e. sex, age, SES, EI and BMI). Coefficients from Model 3 were also converted to non-core energy by multiplying the adjusted ratios by the intercept of the model, to provide meaningful units for public health nutrition. The description and purpose of all different models are illustrated in the online supplementary material, Supplemental Table 1.

For each model, we calculated the change in the proportion of variance explained in the outcome within adolescents, between adolescents and in total compared with the variance estimated by Model 1. For Models 1-3,

Table 1 Characteristics of eating occasions (EO) in the survey and across 'where' and 'with whom' eating contexts, in absolute frequencies and percentages, among adolescents $(n$ 884) aged 11-18 years, UK National Diet and Nutrition Survey (NDNS) $2008-2012$

\begin{tabular}{|c|c|c|c|c|c|c|c|c|c|c|c|c|c|c|c|c|}
\hline & & & & & & & \multicolumn{10}{|c|}{ Meal slots ${ }^{\star}, \ddagger, \S$} \\
\hline & \multicolumn{2}{|c|}{ Total EO } & \multicolumn{2}{|c|}{$\begin{array}{c}\text { Non-core } \\
E O^{\star}, \dagger, \ddagger\end{array}$} & \multicolumn{2}{|c|}{ Weekday $^{*}, \ddagger$} & \multicolumn{2}{|c|}{$\begin{array}{c}06.00-12.00 \\
\text { hours }\end{array}$} & \multicolumn{2}{|c|}{$\begin{array}{c}12.00-14.00 \\
\text { hours }\end{array}$} & \multicolumn{2}{|c|}{$\begin{array}{c}14.00-17.00 \\
\text { hours }\end{array}$} & \multicolumn{2}{|c|}{$\begin{array}{c}17.00-20.00 \\
\text { hours }\end{array}$} & \multicolumn{2}{|c|}{$\begin{array}{c}20.00-06.00 \\
\text { hours }\end{array}$} \\
\hline & $n$ & $\% \|$ & $n$ & $\% \|$ & $n$ & $\% \|$ & $n$ & $\% \|$ & $n$ & $\% \|$ & $n$ & $\% \|$ & $n$ & $\% \|$ & $n$ & $\% \|$ \\
\hline Survey & 19827 & 100 & 13723 & 69 & 13816 & 70 & 5064 & 26 & 3424 & 17 & 3259 & 16 & 4164 & 21 & 3916 & 20 \\
\hline \multicolumn{17}{|l|}{ Whereף } \\
\hline Home & 13517 & 68 & 8909 & 66 & 9093 & 67 & 3502 & 26 & 1342 & 10 & 2161 & 16 & 3400 & 25 & 3112 & 23 \\
\hline $\begin{array}{l}\text { Friend's/relative's } \\
\text { house }\end{array}$ & 932 & 5 & 739 & 79 & 496 & 53 & 137 & 15 & 108 & 12 & 152 & 16 & 247 & 27 & 288 & 31 \\
\hline School & 2359 & 12 & 1713 & 73 & 2329 & 99 & 933 & 40 & 1274 & 54 & 129 & 5 & 17 & 1 & 6 & 0 \\
\hline Eateries & 731 & 4 & 648 & 89 & 403 & 55 & 52 & 7 & 181 & 25 & 148 & 20 & 136 & 19 & 214 & 29 \\
\hline On the go & 1069 & 5 & 878 & 82 & 716 & 67 & 188 & 18 & 234 & 22 & 396 & 37 & 154 & 14 & 97 & 9 \\
\hline $\begin{array}{l}\text { Activity/other } \\
\text { places }\end{array}$ & 816 & 4 & 572 & 70 & 470 & 58 & 131 & 16 & 146 & 18 & 182 & 22 & 172 & 21 & 185 & 23 \\
\hline Work & 403 & 2 & 264 & 66 & 309 & 77 & 121 & 30 & 139 & 34 & 91 & 23 & 38 & 9 & 14 & 3 \\
\hline \multicolumn{17}{|l|}{ With whom } \\
\hline Alone & 4808 & 24 & 2897 & 60 & 3391 & 71 & 1615 & 34 & 561 & 12 & 905 & 19 & 653 & 14 & 1074 & 22 \\
\hline Parents/carers & 2877 & 15 & 1995 & 69 & 1957 & 68 & 752 & 26 & 295 & 10 & 471 & 16 & 797 & 28 & 562 & 20 \\
\hline Parents \& siblings & 2871 & 14 & 2011 & 70 & 1932 & 67 & 628 & 22 & 278 & 10 & 457 & 16 & 987 & 34 & 521 & 18 \\
\hline Family \& friends & 2350 & 12 & 1754 & 75 & 1404 & 60 & 387 & 16 & 275 & 12 & 358 & 15 & 835 & 36 & 495 & 21 \\
\hline Friends & 4618 & 23 & 3564 & 77 & 3605 & 78 & 1158 & 25 & 1632 & 35 & 642 & 14 & 515 & 11 & 671 & 15 \\
\hline Not specified & 2303 & 12 & 1502 & 65 & 1527 & 66 & 524 & 23 & 383 & 17 & 426 & 18 & 377 & 16 & 593 & 26 \\
\hline
\end{tabular}

*Pearson $x^{2}$ test was performed between this variable and with all 'where' and 'with whom' eating contexts.

†EO containing at least one non-core food.

$\ddagger P<0.001$ across all 'where' and 'with whom' eating context.

$\S$ Meal slots are based on NDNS categories.

$\|$ These are percentages of all EO in the whole survey.

IThese are percentages of all EO in the specific context. 
the intraclass correlation (between-adolescent variance/ total variance) represented the proportion of variance in non-core EI attributable to differences between adolescents. Model fit was assessed using a likelihood ratio test.

\section{Sensitivity analyses}

Misreporting for EI was assessed using an individualised method $^{(22,23)}$, where the ratio of reported EI to estimated energy requirement was calculated and plausible reports were identified using cut-offs of $0 \cdot 66-1 \cdot 34$. In total, $53 \%$ of the total sample were under-reporters and $4 \%$ of adolescents were over-reporters. The final Model 3 was rerun with the inclusion of a categorical misreporting variable (under-, plausible or over-reporters); however, ratios were identical to Model 3 and are therefore not reported. Interactions of eating contexts with sex, SES and BMI were tested in Models 4, 5 and 6, respectively. Stratified MLM were run for any statistically significant interactions. Individual level 2 survey weights, available from NDNS, were used to account for selection and non-response bias. Analyses were done in that statistical software package Stata version 13 .

\section{Results}

\section{Characteristics of eating occasions}

Table 1 describes the characteristics of EO overall and within specific eating contexts. The majority of EO were consumed at 'Home' (68\%) and on a weekday (70\%) but were broadly spread throughout the day. Adolescents ate 'Alone' (24\%) as much as with 'Friends' (23\%). Overall $69 \%$ of EO contained non-core food. Similar to all EO, most non-core EO occurred at 'Home' (66\%), on weekdays $(67 \%)$ and were spread throughout the day. EO at 'Home' (68\%) were less likely to be with 'Friends' (5\%) and more likely to occur 'Alone' (33\%; data not shown). While 3\% of all EO occurred in 'Eateries' (see online supplementary material, Supplemental Table 2), 89\% contained non-core food. EO at 'Eateries' were more likely to occur with 'Friends' (51\%) and less likely to occur with 'Parents/carers' (9\%; data not shown). Eating 'Alone' was less likely to contain non-core food (60\%) and was more common in the morning ( $34 \%$ at $06.00-12.00$ hours). EO with 'Friends' were more likely to contain non-core food (77\%) and occur on a weekday (78\%) lunchtime (35\% at 12.00-14.00 hours).

\section{Characteristics of adolescents}

Table 2 describes individual characteristics of adolescents reporting EO overall and within different physical and social eating contexts. All adolescents reported eating at 'Home' and $63 \%$ ate at 'School'. Fewer adolescents reported eating in other locations, ranging from 12 to $50 \%$ reporting eating at 'Work' or 'On the go'. Overall the mean age of adolescents was 14.5 years, mean BMI was $21.9 \mathrm{~kg} / \mathrm{m}^{2}$, BMI $Z$-score was 0.7 and mean total EI was $7468 \mathrm{~kJ} / \mathrm{d}$

Table 2 Characteristics of adolescents $(n$ 884) aged $11-18$ years in the UK National Diet and Nutrition Survey (NDNS) 2008-2012

\begin{tabular}{|c|c|c|c|c|c|c|c|c|c|c|c|c|c|c|c|c|c|c|c|c|}
\hline & \multicolumn{2}{|c|}{ Adolescents } & \multicolumn{2}{|c|}{ Boys* } & \multicolumn{2}{|c|}{$\begin{array}{l}\text { High } \\
\text { SES† }\end{array}$} & \multicolumn{2}{|c|}{$\begin{array}{c}\text { Intermediate } \\
\text { SES }\end{array}$} & \multicolumn{2}{|c|}{$\begin{array}{c}\text { Age } \\
\text { (years)† }\end{array}$} & \multicolumn{2}{|c|}{$\begin{array}{c}\mathrm{BMI} \\
\left(\mathrm{kg} / \mathrm{m}^{2}\right) \dagger\end{array}$} & \multicolumn{2}{|c|}{$\begin{array}{c}\text { BMI } \\
\text { Z-score†, }\end{array}$} & \multicolumn{2}{|c|}{$\begin{array}{l}\text { Total El } \\
(\mathrm{kJ} / \mathrm{d}) \dagger\end{array}$} & \multicolumn{2}{|c|}{$\begin{array}{l}\text { Total El } \\
(\mathrm{kcal} / \mathrm{d}) \dagger\end{array}$} & \multicolumn{2}{|c|}{$\begin{array}{c}\text { Total EO/ } \\
\text { person } \\
\text { per d† }\end{array}$} \\
\hline & $n$ & $\%$ & $n$ & $\%$ & $n$ & $\%$ & $n$ & $\%$ & Mean & SD & Mean & SD & Mean & SD & Mean & SD & Mean & $\mathrm{SD}$ & Mean & SD \\
\hline Survey & 884 & 100 & 445 & 50 & 362 & 41 & 167 & 19 & 14.5 & 2.2 & 21.9 & 4.4 & 0.7 & $1 \cdot 2$ & 7468 & 2176 & 1785 & 520 & $6 \cdot 4$ & 2.5 \\
\hline \multicolumn{21}{|l|}{ Where } \\
\hline Home & 883 & 100 & 444 & 50 & 362 & 41 & 167 & 19 & 14.5 & $2 \cdot 2$ & 21.9 & 4.4 & 0.7 & $1 \cdot 2$ & 7473 & 2176 & 1786 & 520 & 3. 8 & $2 \cdot 0$ \\
\hline $\begin{array}{l}\text { Friend's/relative's } \\
\text { house }\end{array}$ & 315 & 36 & 148 & 47 & 134 & 43 & 55 & 17 & $14 \cdot 6$ & $2 \cdot 2$ & $21 \cdot 8$ & $4 \cdot 1$ & 0.6 & $1 \cdot 2$ & 7494 & 2146 & 1791 & 513 & 0.3 & 0.8 \\
\hline School & 554 & 63 & 286 & 52 & 238 & 43 & 105 & 19 & $13 \cdot 8$ & $2 \cdot 1$ & $21 \cdot 6$ & 4.4 & 0.7 & $1 \cdot 2$ & 7481 & 2084 & 1788 & 498 & 0.7 & $1 \cdot 1$ \\
\hline Eateries & 324 & 37 & 155 & 48 & 145 & 45 & 62 & 19 & $15 \cdot 0$ & $2 \cdot 2$ & 21.9 & $4 \cdot 1$ & 0.6 & $1 \cdot 2$ & 7971 & 2197 & 1905 & 525 & 0.2 & 0.7 \\
\hline On the go & 445 & 50 & 218 & 49 & 185 & 42 & 82 & 18 & $14 \cdot 6$ & $2 \cdot 2$ & $22 \cdot 1$ & 4.7 & 0.7 & $1 \cdot 2$ & 7832 & 2264 & 1872 & 541 & 0.3 & 0.7 \\
\hline $\begin{array}{l}\text { Activity/other } \\
\text { places }\end{array}$ & 337 & 38 & 177 & 53 & 156 & 46 & 63 & 19 & 14.5 & $2 \cdot 2$ & 21.9 & $4 \cdot 2$ & 0.8 & $1 \cdot 1$ & 7774 & 2176 & 1858 & 520 & 0.2 & 0.7 \\
\hline Work & 108 & 12 & 45 & 42 & 42 & 39 & 27 & 25 & $16 \cdot 4$ & $2 \cdot 0$ & $23 \cdot 1$ & 4.6 & 0.7 & $1 \cdot 3$ & 7523 & 2360 & 1798 & 564 & 0.1 & 0.6 \\
\hline \multicolumn{21}{|l|}{ With whom } \\
\hline Alone & 776 & 88 & 388 & 50 & 334 & 43 & 146 & 19 & $14 \cdot 7$ & $2 \cdot 2$ & 21.9 & 4.4 & 0.7 & $1 \cdot 2$ & 7498 & 2247 & 1792 & 537 & 1.4 & 1.5 \\
\hline Parents/carers & 596 & 67 & 293 & 49 & 253 & 42 & 109 & 18 & 14.4 & $2 \cdot 2$ & $21 \cdot 8$ & 4.5 & 0.7 & $1 \cdot 2$ & 7548 & 2239 & 1804 & 535 & 0.8 & $1 \cdot 3$ \\
\hline $\begin{array}{l}\text { Parents \& } \\
\text { siblings }\end{array}$ & 496 & 56 & 245 & 49 & 203 & 41 & 98 & 20 & $14 \cdot 2$ & $2 \cdot 2$ & $21 \cdot 6$ & $4 \cdot 2$ & 0.7 & $1 \cdot 2$ & 7468 & 2138 & 1785 & 511 & 0.8 & 1.4 \\
\hline Family \& friends & 508 & 57 & 245 & 48 & 205 & 40 & 98 & 19 & 14.4 & $2 \cdot 2$ & $21 \cdot 8$ & $4 \cdot 3$ & 0.7 & $1 \cdot 2$ & 7519 & 2117 & 1797 & 506 & 0.7 & $1 \cdot 2$ \\
\hline Friends & 773 & 87 & 382 & 49 & 321 & 42 & 148 & 19 & 14.5 & $2 \cdot 2$ & 21.9 & 4.5 & 0.7 & $1 \cdot 2$ & 7519 & 2201 & 1797 & 526 & $1 \cdot 3$ & 1.7 \\
\hline Not specified & 464 & 52 & 244 & 53 & 168 & 36 & 95 & 20 & 14.5 & $2 \cdot 3$ & 21.9 & 4.3 & 0.7 & $1 \cdot 2$ & 7586 & 2184 & 1813 & 522 & 0.7 & $1 \cdot 3$ \\
\hline
\end{tabular}

SES, socio-economic status; El, energy intake; EO, eating occasion.

Pearson $x^{2}$ test was performed between sex, high SES, intermediate SES and all 'where' and 'with whom' eating contexts.

Kruskal-Wallis test was performed between mean age, BMI, BMI Z-score, total El and total EO/person per d with all 'where' and 'with whom' eating contexts.

*Evidence of association only for 'with whom' eating contexts $(P<0.001)$.

†Evidence of association for both 'where' and 'with whom' eating contexts $(P<0.001)$.

†BMI Z-score was created by standardising BMI for sex and age based on the 1990 British Growth Reference ${ }^{(19)}$. 
(1785 kcal/d). Adolescents reported on average $6.4 \mathrm{EO} /$ person per $\mathrm{d}$.

Adolescents who ate at 'Eateries' were mostly females, older, of higher SES and had greater total EI $(7971 \mathrm{~kJ} / \mathrm{d}$ (1905 kcal/d)) compared with the overall sample. On the contrary, their BMI $Z$-score was lower compared with the children of the UK child growth standards ( $0 \cdot 6 v \cdot 0 \cdot 7)$. Adolescents had on average $0.2 \mathrm{EO} /$ person per $\mathrm{d}$ at 'Eateries'. Finally, adolescents who ate with 'Friends' had $1.3 \mathrm{EO} /$ person per $\mathrm{d}$ on average eating with them and did not differ from the overall sample in terms of their overall characteristics.

Compared with the overall sample of adolescents, boys were less likely to eat at a 'Friend's/relative's house', 'Eateries', 'Work' and with 'Family \& friends' and more likely to eat at 'Activity/other places' and with people 'Not specified' (see online supplementary material, Supplemental Table 3). Adolescents from the high SES group were more likely to eat at 'Eateries' and 'Activity/other places' and with 'Parents/carers' compared with the overall sample (Supplemental Table 3), while adolescents from the intermediate SES group were more likely to eat at 'Work' and with 'Parents \& siblings' compared with the overall sample (Supplemental Table 3).

\section{Witbin- and between-adolescent variation in non- core energy intake}

In Model 1 including random effects for adolescents, the intraclass correlation showed that only $11 \%$ of the total variance in non-core EI was attributed to differences between adolescents (Table 3 ). The remaining $89 \%$ of the differences in non-core EI was attributed to within-person variability in different $\mathrm{EO}$.

Including level 1 variables (characteristics of EO) explained $4.8 \%$ of the total variation and $5.1 \%$ of the variation within adolescents in non-core EI (Model 2,
Table 3). Further adjusting for adolescents' characteristics in Model 3, we explained $20 \cdot 2 \%$ of the betweenadolescent variation in non-core EI and $6.5 \%$ of the total variance compared with Model 1 (Model 3, Table 3). Only sex, total EI and BMI showed evidence of an association with non-core EI, which individually explained $0 \cdot 3,2 \cdot 3$ and $0.3 \%$ of the total variation, respectively (Table 4 ). The association of sex with non-core EI was attenuated by the inclusion of covariates in Model 3, but associations for total EI and BMI $Z$-score remained (data not shown). In Model 3, each $4184 \mathrm{~kJ}(1000 \mathrm{kcal})$ of total EI was associated with $42 \%$ (95\% CI 30, 55\%) more non-core EI, while 1 SD of BMI was associated with $4 \%$ (95\% CI 0, 7\%) lower non-core EI in an EO. The intraclass correlation in Model 3 decreased to $9 \cdot 3 \%$, suggesting that by including the above adolescent characteristics, $9.3 \%$ of the differences in non-core energy were now attributed to differences between adolescents. The fit of the models improved significantly (Table 3).

\section{Associations of physical ('where') contexts with non-core energy intake}

The effect estimates and variation explained for physical eating contexts in Model 1.1 are displayed in Table 4. Eating at 'Eateries' was associated with the largest noncore EI, with intakes more than double the amount eaten at 'Home' $(2.79$; $95 \%$ CI 2.41, 3.24). All the remaining locations showed evidence, to a much lesser extent, of higher non-core EI compared with 'Home'. Collectively 'where' EO occurred explained $4.1 \%$ of the total variance in non-core energy (Table 4).

After adjusting for EO and adolescent characteristics (Model 3), evidence for higher non-core EI in all out-ofhome locations was robust (Table 5). The effect size of all locations on non-core EI was broadly similar in Model 3 compared with the unadjusted Model 1·1 (Table 4). After

Table 3 Within-adolescent, between-adolescent and total variance explained across the different models among adolescents ( $n$ 884) aged 11-18 years in the UK National Diet and Nutrition Survey (NDNS) 2008-2012

\begin{tabular}{|c|c|c|c|c|c|c|}
\hline & \multirow[b]{2}{*}{ Model $1^{*}$} & \multirow[b]{2}{*}{ Model $2 \dagger$} & \multirow[b]{2}{*}{ Model 3‡ } & \multicolumn{3}{|c|}{ Interaction models } \\
\hline & & & & Model $4 \S$ & Model 5\| & Model 6ा \\
\hline Within-adolescent variance explained ${ }^{\star \star}(\%)$ & $\mathrm{N} / \mathrm{A}$ & $5 \cdot 1$ & 4.9 & $5 \cdot 1$ & $5 \cdot 6$ & $5 \cdot 0$ \\
\hline Between-adolescent variance explained ${ }^{\star *}(\%)$ & N/A & $1 \cdot 7$ & $20 \cdot 2$ & $19 \cdot 8$ & $21 \cdot 5$ & $20 \cdot 4$ \\
\hline Total variance explained ${ }^{\star *}(\%)$ & N/A & $4 \cdot 8$ & 6.5 & 6.7 & $7 \cdot 4$ & $6 \cdot 6$ \\
\hline ICC†† (\%) & 10.9 & $11 \cdot 3$ & $9 \cdot 3$ & 9.4 & $9 \cdot 3$ & $9 \cdot 3$ \\
\hline Log-maximum likelihood & 22639 & $22310 \neq \ddagger$ & $21235 \ddagger \ddagger$ & 21219 㧊 & 21572 & $21228 \ddagger \ddagger$ \\
\hline
\end{tabular}

ICC, intraclass correlation; SES, socio-economic status; N/A, not applicable.

*Model 1 includes just adolescents' identifier to model random effects within and between people. No explanatory variables are included.

†Model 2 is adjusted for within-adolescent variables, i.e. 'where and 'with whom' eating contexts, time of day and day of the week.

¥Model 3 is adjusted for within-adolescent variables (from Model 2) and for between-adolescent variables, i.e. sex, age, BMI, energy intake and SES.

$\S$ Model 4 is adjusted for within- and between-adolescent variables (Model 3) and sex-eating contexts interactions.

IIModel 5 is adjusted for within- and between-adolescent variables (Model 3) and SES-eating contexts interactions.

TModel 6 is adjusted for within- and between-adolescent variables (Model 3) and BMl-eating contexts interactions.

${ }^{\star *}$ Computed as the percentage of change in variance compared with Model 1.

††ICC represents the percentage of variation in non-core energy intake in an eating occasion attributed to differences between adolescents. Computed from $I C C=$ between-adolescents' variance/total variance.

$\ddagger \ddagger P<0.001$. A likelihood ratio test was conducted by comparing the deviance across the models. The difference in deviance follows a $x^{2}$ distribution with df, the increase in the number of parameters estimated in each successive model $(\mathrm{df}=1)$. 
Table 4 Relationship of non-core energy intake with eating occasion (EO) and adolescent variables, along with percentage of total variance explained, among adolescents ( $n$ 884) aged 11-18 years in the UK National Diet and Nutrition Survey (NDNS) 2008-2012

\begin{tabular}{|c|c|c|c|c|c|}
\hline & Model & Ratio & $95 \% \mathrm{Cl}$ & $P$ value & $\begin{array}{l}\text { Total variance } \\
\text { explained }(\%)^{\star}\end{array}$ \\
\hline \multicolumn{6}{|l|}{ EO level } \\
\hline Friend's/relative's house† & Model 1.1 & 1.39 & $1.21,1.59$ & 0.001 & $4 \cdot 1$ \\
\hline Schoolt & & 1.82 & $1.65,1.99$ & 0.001 & \\
\hline Eateries $\dagger$ & & 2.79 & $2.41,3.24$ & 0.001 & \\
\hline On the got & & 1.77 & $1.60,1.97$ & 0.001 & \\
\hline Activity/other places $†$ & & 1.38 & $1 \cdot 16,1.64$ & 0.001 & \\
\hline Workt & & 1.29 & $1.06,1.57$ & 0.013 & \\
\hline Parents/carersł & Model 1.2 & 1.06 & $0.95,1.18$ & 0.322 & $2 \cdot 1$ \\
\hline Parents \& siblings $\ddagger$ & & $1 \cdot 15$ & $1.02,1.29$ & 0.018 & \\
\hline Family \& friends $\ddagger$ & & 1.37 & $1.22,1.54$ & 0.001 & \\
\hline Friendsł & & 1.80 & $1.63,1.99$ & 0.001 & \\
\hline Not specified $\ddagger$ & & $1 \cdot 19$ & $1.05,1.35$ & 0.008 & \\
\hline Time of day (per hour) & Model 1.3 & 1.01 & $1.00,1.02$ & 0.001 & 0.1 \\
\hline Day of the week & Model 1.4 & 1.04 & $0.98,1.10$ & 0.234 & 0.0 \\
\hline \multicolumn{6}{|l|}{ Adolescent level } \\
\hline Sex & Model 1.5 & 0.85 & $0.78,0.92$ & 0.001 & 0.3 \\
\hline Age & Model 1.6 & 1.02 & $1.00,1.04$ & 0.069 & $0 \cdot 1$ \\
\hline BMl Z-score & Model 1.7 & 0.95 & $0.92,0.99$ & 0.008 & 0.3 \\
\hline Energy intake (per 4184 kJ (1000 kcal)) & Model 1.8 & 1.53 & $1.42,1.66$ & 0.001 & $2 \cdot 3$ \\
\hline High SES & Model 1.9 & 0.98 & $0.89,1.07$ & 0.611 & 0.0 \\
\hline Intermediate SES & & 0.92 & $0.81,1.05$ & 0.226 & \\
\hline
\end{tabular}

SES, socio-economic status.

Ratios come from linear variance component multilevel models (Models 1.1 to 1.9), with non-core energy intake (non-core kcal) as the outcome variable. Models 1.1 and 1.2 with eating contexts contain all dummy variables for the physical or the social contexts examined. For example, Model 1.1 includes all the dummy variables for the 'where' variable, e.g. 'Friend's/relative's house', 'School', 'Eateries', 'On the go', 'Activity/other places' and 'Work', with the reference category being 'Home'. Similarly, Model 1.2 includes 'Parents/carers', 'Parents \& siblings', 'Family \& friends', 'Friends' and 'Not specified', with the reference category being 'Alone'. All the remaining models contain one independent variable. Ratios are the exponentiated values of the log-transformed coefficients and represent changes in the ratio of the mean non-core energy intake (kcal) in an eating occasion (the intercept). For example, an exponentiated value of 1.39 for an eating context represents a $39 \%$ difference in non-core energy intake between the specified eating context and its reference category.

${ }^{*}$ Computed as the percentage of change in total variance compared with Model 1.

†Reference category is 'Home'.

†Reference category is 'Alone'.

Table 5 Ratios of the change in mean non-core energy intake at each 'where' and 'with whom' eating context among adolescents ( $n$ 884) aged 11-18 years in the UK National Diet and Nutrition Survey (NDNS) 2008-2012

\begin{tabular}{|c|c|c|c|}
\hline & Estimate/ratio & $95 \% \mathrm{Cl}$ & $P$ value \\
\hline \multicolumn{4}{|l|}{ Estimate* $^{*}$} \\
\hline Intercept & $67 \cdot 0$ & $47.84,93.93$ & 0.001 \\
\hline \multicolumn{4}{|l|}{ Ratio* } \\
\hline Friend's/relative's house† & $1 \cdot 25$ & $1.07,1.46$ & 0.004 \\
\hline Schoolt & 1.88 & $1 \cdot 65,2 \cdot 13$ & 0.001 \\
\hline Eateries† & 2.51 & $2 \cdot 12,2 \cdot 96$ & 0.001 \\
\hline On the got & 1.75 & $1.56,1.96$ & 0.001 \\
\hline Activity/other places $\dagger$ & 1.34 & $1.12,1.61$ & 0.002 \\
\hline Workt & 1.28 & $1.05,1.57$ & 0.015 \\
\hline Parents/carers $\ddagger$ & 1.01 & $0.91,1.13$ & 0.816 \\
\hline Parents \& siblings $\ddagger$ & $1 \cdot 10$ & $0.98,1.23$ & $0 \cdot 122$ \\
\hline Family \& friends $\ddagger$ & 1.21 & $1.07,1.37$ & 0.002 \\
\hline Friends $\ddagger$ & $1 \cdot 16$ & $1.03,1.31$ & 0.014 \\
\hline Not specified $\ddagger$ & 0.93 & $0.82,1.06$ & 0.296 \\
\hline
\end{tabular}

*Estimate and ratios come from Model 3 (adjusted for 'where and 'with whom' eating contexts, time of day, day of the week, sex, age, BMI, energy intake and socio-economic status). Ratios are the exponentiated values of the log-transformed coefficients and represent changes in the ratio of the mean non-core energy intake (kcal) in an eating occasion (the intercept). For example, an exponentiated value of 1.25 for an eating context represents a $25 \%$ difference in non-core energy intake between the specified eating context and its reference category.

†Reference category is 'Home'.

‡Reference category is 'Alone'.

these adjustments, 'Eateries' remained associated with the highest non-core EI $(2 \cdot 51 ; 95 \%$ CI $2 \cdot 12,2 \cdot 96)$, followed by 'School' (1.88; $95 \%$ CI 1.65, 2.13).

Associations of locations with non-core energy are presented in Fig. 1 in units of kcal/EO. Assuming all else is equal, when adolescents eat in 'Eateries', their non-core EI is 703 (95\% CI 427, 1163) kJ (168 (95\% CI 102, 278) kcal) compared with 280 (95\% CI 201, 393) kJ (67 (95\% CI 48, 94) kcal) when they eat at 'Home'. 
Associations of social ('with whom') contexts with non-core energy intake

The effect estimates and variation explained for social eating contexts in Model 1.2 are displayed in Table 4. In the unadjusted models (Table 4), when eating with 'Friends', adolescents consumed $80 \%$ more non-core EI (1.80; $95 \%$ CI 1.63, 1.99) compared with eating 'Alone'. On the contrary, when eating with 'Parents \& siblings', adolescents reported eating $15 \%(1.15$; $95 \%$ CI 1.02, 1.29) more non-core energy compared with eating 'Alone'. Collectively 'with whom' adolescents ate explained 2.1\% of the variance in non-core energy (Table 4).

After adjusting for $\mathrm{EO}$ and adolescent characteristics (Model 3, Table 5), eating with 'Family \& friends' was the social context with the highest non-core EI compared with eating 'Alone' (21\%; $95 \%$ CI 7, 37\%), whereas the association with 'Friends' was greatly attenuated to just $16 \%$ (95\% CI 3, 31\%) more non-core EI.

Associations of social eating contexts with non-core energy represent adolescents consuming 335 (95\% CI 213, $536) \mathrm{kJ}(80(95 \%$ CI 51, 128) kcal) and 318 (95\% CI 205, $515) \mathrm{kJ}(76(95 \% \mathrm{CI} 49,123) \mathrm{kcal})$ non-core EI when with 'Family \& friends' and 'Friends', respectively, compared

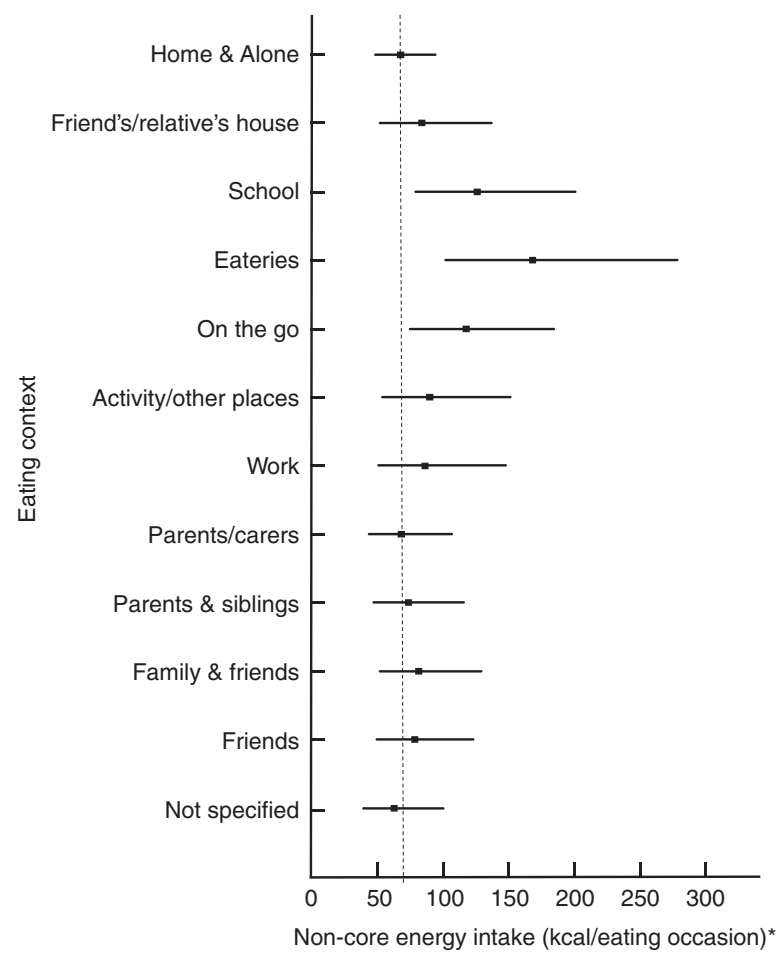

Fig. 1 Associations of eating contexts with non-core energy intake among adolescents ( $n$ 884) aged $11-18$ years, UK National Diet and Nutrition Survey (NDNS) 2008-2012. *Predicted estimates come from Model 3, adjusted for time of day, day of the week, sex, age, BMI, energy intake and socioeconomic status. Computed from Table 5 (estimate $=$ intercept $\times$ ratio), they show non-core energy (in kcal/eating occasion; $1 \mathrm{kcal}=4.184 \mathrm{~kJ}$ ) that adolescents consume in all eating contexts, with $95 \% \mathrm{Cl}$ represented by horizontal bars. - . - - shows non-core energy intake at 'Home' and 'Alone' (intercept), adjusted for factors in Model 3 (mentioned above) with 280 (95\% CI 201, 393) kJ (67 (95\% CI 48, 94) kcal) when eating 'Alone' (Fig. 1).

\section{Interactions between sex and eating contexts on non-core energy intake}

Evidence of interaction was observed only for sex and 'Activity/other places' $(P=0.045)$ as well as 'Family \& friends' ( $P=0.028)$. Boys consumed $48 \%$ more non-core energy at 'Activity/other places' compared with girls (boys: 1.56; $95 \%$ CI 1.22, 1.98; girls: 1.08; $95 \%$ CI 0.83, 1.42), whereas girls consumed $29 \%$ more non-core energy compared with boys when eating with 'Family \& friends' (girls: 1.35; $95 \%$ CI 1.14, 1.59; boys: 1.06; $95 \%$ CI 0.90, 1.25).

\section{Discussion}

The present study is the first assessing the associations between eating contexts and non-core energy consumption independent of other features of EO and individual adolescent characteristics. Only $11 \%$ of the variation in non-core EI was attributed to differences between adolescents, while the remaining $89 \%$ occurred because of differences from one EO to another within the same person. Eateries, such as restaurants, cafés and fast-food places, were independently associated with the highest non-core EI, where adolescents consumed $423 \mathrm{~kJ}$ (101 kcal)/EO more non-core energy than comparable EO at home. Analyses to date have only captured how differences between people are associated with non-core EI, such as food preferences or amounts of television watching ${ }^{(24,25)}$. By using MLM, the association of eating contexts independent of between-individual differences was estimated and thus potential confounding associated with adolescents' specific characteristics was ruled out.

As our analysis is novel there are no other studies with which to directly compare the results. Previous research has either focused on the associations of different food environments with overall consumption, without distinguishing between 'healthy' and 'unhealthy' foods ${ }^{(26,27)}$, or has only examined younger children's individual characteristics in relation to non-core energy consumption $^{(24,25,28)}$. Mak et al. ${ }^{(12)}$ have examined associations of eating context with fruit and vegetable consumption in a younger age group, showing lower odds of fruit and vegetable consumption at home compared with school and care outside home settings. In addition, Liu et al. ${ }^{(13)}$ showed that adults had higher odds of consuming sugarsweetened beverages outside the home and especially in sit-down restaurants and fast-food/convenience stores, similarly to our findings. However, none of these studies reported on the relative contribution of within- and between-person variation to food intake, unlike our findings. Our analyses showed greater within-person variability in non-core food intake, suggesting that 
interventions should target environmental contexts rather than individual characteristics to reduce adolescents' noncore food consumption.

Non-core EI was more variable from one EO to another (within adolescents) than it was from one person to another (between adolescents), suggesting that all adolescents eat non-core energy to some extent. The amount of non-core energy they eat is better predicted by characteristics of EO, such as where and with whom the EO occurred, rather than characteristics of the individual like their age or SES. Future research should therefore focus on identifying factors affecting within-person variability in EO rather than the characteristics of people; for example, food advertising, product placement and number of people present. These factors, among others, can vary between EO, however they are typically measured in laboratory settings. Collecting information on these factors in real-life settings may help us explain a greater proportion of within-person variation in non-core EI and identify novel targets for interventions. Changing individuals' eating behaviour can be notoriously hard, thus interventions could instead target specific eating environments to help everyone reduce non-core energy in those contexts ${ }^{(29)}$. The focus of policies could be further guided by understanding the source of non-core energy; for example, if most non-core energy eaten at school is bought from nearby food outlets then policies improving the food environment of those outlets would be beneficial.

Eateries were the eating contexts associated with the highest non-core energy consumption in adolescents. On average adolescents had 0.2 non-core $\mathrm{EO}$ at eateries per day and ate $423 \mathrm{~kJ}$ (101 kcal) more non-core energy in each EO, which translates to 590 more $\mathrm{kJ}$ (141 more kcal) of non-core energy per week compared with eating at home. Although most eating occasions take place at home and therefore in absolute terms more non-core food is consumed at home, adolescents are less likely to consume non-core food at home compared with eating in eateries. In addition, our analyses did not consider food purchased from eateries but consumed elsewhere, which is likely to have increased non-core food consumed at/from eateries. Adolescents choose to eat at eateries such as fast-food places because they are quick, easy to get to and they serve tasty foods ${ }^{(30)}$. Foods consumed in eateries are usually higher in fat and sugar than foods consumed at home ${ }^{(31)}$, which is in concordance with our work showing higher non-core EI in these settings. In addition, portion sizes served at eateries in the UK have increased over the years ${ }^{(32)}$. Hence, factors such as an increased availability of non-core foods at eateries, larger portion sizes and the frequency with which adolescents eat there, may explain the increased non-core EI at these places. Reformulating non-core foods, offering a different range of foods (e.g. fruit and vegetables as side dishes rather than chips ${ }^{(33)}$ ) and decreasing portion sizes have been suggested as strategies to decrease non-core food consumption ${ }^{(34)}$.
A few of these strategies have been tried among adolescents and were shown to be successful ${ }^{(35,36)}$, thus future studies should further explore their use in real-life settings.

Despite existing policies to improve the quality of food in schools ${ }^{(37)}$, our findings highlighted greater amounts of non-core foods consumed in school compared with home. School food standards have generally improved the quality of schools meals provided in secondary schools ${ }^{(38)}$; however, nutrients such as fibre, vitamins and Fe were still below recommended standards ${ }^{(38)}$. In addition, some academies and free schools are still exempt, hence the quality of food provided there cannot be ensured. A substantial source of food consumed in schools is packed lunches, whose nutritional quality is considered poorer compared with school meals ${ }^{(38-40)}$. Furthermore, adolescents often buy non-core foods, such as soft drinks and confectionery, from supermarkets, fast-food places and convenience shops ${ }^{(41)}$, typically found around school premises $^{(42)}$. Future studies should also explore where most of the non-core food consumed at schools is obtained from, to better guide the focus of school interventions and policies.

Eating with family and friends and with friends were the only social eating contexts associated with increased noncore EI compared with eating alone. Previous research has shown increased EI with familiar others compared with strangers ${ }^{(43)}$; that is, greater meal size (more energy consumed) when eating with family/spouse and friends compared with co-workers and other unfamiliar peo$\mathrm{ple}^{(44)}$. Social facilitation was suggested as the operating mechanism, i.e. people consume more food in the presence of familiar others ${ }^{(44,45)}$. In addition, more often than not, eating with family and friends occurs in eateries compared with eating alone or with parents and siblings, i.e. 7 v. $0 \cdot 2-2 \%$ (data not shown). Eating with family and friends represents a social occasion which is considered a 'treat' for the whole family ${ }^{(46)}$, hence non-core food choices become more acceptable compared with the home environment. Future studies should explore ways to normalise core food consumption when eating out in the company of family and friends.

Our findings highlighted high-risk eating environments, such as eateries and school; however, the majority of EO and subsequently non-core food consumption still occurred within the home environment. To improve the home eating environment, we need to understand the sources of non-core food consumed at home, which will enable us to identify additional targets for home-based interventions. Evidence shows that British adolescents obtain most of their fat and sugar intake from fast-food places, bakeries, convenience shops and vending machines ${ }^{(47)}$, while US data from four national representative surveys from 19772006 have shown that most of the energy adolescents consumed at home was obtained from supermarkets and grocery shops ${ }^{(48)}$. Future studies should investigate place of consumption and place of purchase concurrently, to 
more efficiently target and change high-risk eating environments.

\section{Strengths and limitations}

Our findings should be interpreted carefully in the light of the study's strengths and limitations. A major strength is that data are from a representative adolescent sample in the UK and that foods were classified to core and non-core with the use of a simple and explicit tool. The use of MLM allowed us to investigate the independent association of eating context within-person, while holding betweenperson confounding factors constant. Food diaries offer a more accurate dietary assessment method compared with an FFQ or a single $24 \mathrm{~h}_{\text {recall }}{ }^{(49)}$, while their combination with EMA allowed the collection of real-time data and the simultaneous measure of contextual factors alongside food intake. All self-reported dietary assessment can be affected by misreporting; however, we quantified and adjusted for plausible reporting in our analyses ${ }^{(22,50)}$ and the results were unchanged.

On the other hand, the use of cross-sectional data limits causal inference. The study did not investigate the combined association of physical and social eating contexts, such as eating with friends at school, as this type of analysis would decrease the power to detect interactions owing to the small numbers in some contextual combinations. Eating location was defined as the place of consumption, however looking at the place of purchase may have identified different eating contexts such as convenience stores. The total variance of non-core EI explained in the models was relatively small (i.e. 6.7\%), hence future research should explore further withinperson variability by measuring additional factors ${ }^{(51)}$ like food availability and accessibility of food outlets. These are typically perceived to vary between people but could also be measured at that EO level. Finally, the definition of eateries in the current study included both sit-down restaurants and fast-food places, although poor diet quality has been mainly attributed to fast-food outlets rather than sit-down restaurants or cafés ${ }^{(52)}$. However, EO at fast-food outlets in our data represented a very small proportion of total EO $(0.8 \%)$, hence associations with fast-food restaurants only would be unlikely to be different compared with overall eateries.

\section{Conclusion}

The present study is the first to analyse associations of eating context with UK adolescents' non-core energy consumption, independent of their individual characteristics. Variability in non-core EI is better explained by differences between EO rather than between individuals, hence targeting specific high-risk food environments and not specific people may be more beneficial for improving adolescents' eating behaviour and subsequently their diet during adulthood. More specifically, our findings highlight the potential for targeting eateries in future interventions to reduce non-core energy consumption, through reformulation of existing non-core foods, the provision of smaller portion sizes or increasing the availability of healthier food choices. By improving the food environment of eateries, as well as other high-risk eating environments such as school, consumption of healthier options becomes easier, while diet inequalities are more likely to reduce since change occurs for everyone ${ }^{(29)}$. A great proportion of unexplained within-person variability in non-core EI was highlighted which suggests that future research should focus on identifying factors affecting EO rather than individual characteristics.

\section{Acknowledgements}

Acknowledgements: The authors would like to thank the study participants, the NDNS team, the UK Data Service and the dietary assessment assistants at MRC Human Nutrition Research who coded the food diaries. Financial support: This research received no specific grant from any funding agency in the public, commercial or non-for-profit sectors. Conflict of interest: None. Authorship: The present work was designed by Z.T., A.M.H. and L.J.; analysis was conducted by Z.T., L.J. and K.T.; initial manuscript preparation and drafts were prepared by Z.T.; the final manuscript was revised by all authors. Ethics of human subject participation: The NDNS was conducted according to the Declaration of Helsinki and was approved by the Oxfordshire A Research Ethics Committee. Written informed consent was obtained from all participants.

\section{Supplementary material}

To view supplementary material for this article, please visit https://doi.org/10.1017/S1368980018002860

\section{References}

1. Forouzanfar MH, Alexander L, Anderson HR et al. (2015) Global, regional, and national comparative risk assessment of 79 behavioural, environmental and occupational, and metabolic risks or clusters of risks in 188 countries, 19902013: a systematic analysis for the Global Burden of Disease Study 2013. Lancet 386, 2287-2323.

2. Bates B, Cox L, Nicholson SK et al. (2014) National Diet and Nutrition Survey: Results from Years 1, 2, 3 and 4 (combined) of the Rolling Programme (2008/2009-2011/ 2012). London: Public Health England; available at https:// www.gov.uk/government/uploads/system/uploads/attachment_ data/file/310995/NDNS_Y1_to_4_UK_report.pdf

3. Llauradó E, Albar SA, Giralt M et al. (2016) The effect of snacking and eating frequency on dietary quality in British adolescents. Eur J Nutr 55, 1789-1797. 
4. Bates B, Cox L, Nicholson SK et al. (2016) National Diet and Nutrition Survey. Results from Years 5 and 6 (combined) of the Rolling Programme (2012/2013-2013/2014). London: Public Health England; available at https://www.gov.uk/ government/uploads/system/uploads/attachment_data/ file/551352/NDNS_Y5_6_UK_Main_Text.pdf

5. Adamson A, Spence S, Reed L et al. (2013) School food standards in the UK: implementation and evaluation. Public Health Nutr 16, 968-981.

6. World Health Organization (2012) Prioritizing Areas for Action in the Field of Population-Based Prevention of Childhood Obesity: A Set of Tools for Member States to Determine and Identify Priority Areas for Action. Geneva: WHO; available at http://apps.who.int/iris/bitstream/ 10665/80147/1/9789241503273_eng.pdf?ua=1

7. Toumpakari Z, Haase AM \& Johnson L (2016) Adolescents' non-core food intake: a description of what, where and with whom adolescents consume non-core foods. Public Health Nutr 19, 1645-1653.

8. Public Health England (2016) The Eatwell Guide Booklet. London: Public Health England; available at https://www. gov.uk/government/uploads/system/uploads/attachment_ data/file/528200/Eatwell_guide_booklet.pdf

9. National Health and Medical Research Council (2013) Eat for Health: Educator Guide. Canberra: NHMRC; available at https://www.eatforhealth.gov.au/sites/default/files/files/ the_guidelines/n55b_eat_for_health_educators_guide.pdf

10. Briggs L \& Lake AA (2011) Exploring school and home food environments: perceptions of 8-10-year-olds and their parents in Newcastle upon Tyne, UK. Public Health Nutr 14, $2227-2235$.

11. Story M, Neumark-Sztainer D \& French S (2002) Individual and environmental influences on adolescent eating behaviors. J Am Diet Assoc 102, 3 Suppl., S40-S51.

12. Mak T, Prynne C, Cole D et al. (2012) Assessing eating context and fruit and vegetable consumption in children: new methods using food diaries in the UK National Diet and Nutrition Survey Rolling Programme. Int J Behav Nutr Phys Act 9, 126.

13. Liu JL, Han B \& Cohen DA (2015) Associations between eating occasions and places of consumption among adults. Appetite 87, 199-204.

14. UK Data Archive (2010) National Diet and Nutrition Survey Years 1-4, 2008/09-2011/12. https://discover.ukdataservice. ac.uk/catalogue?sn=6533 (accessed April 2013).

15. Lennox A, Fitt E, Whitton C et al. (2014) Appendix A: Dietary Data Collection and Editing. National Diet and Nutrition Survey Years 1-4 (2008/09-2011/12). London: Public Health England; available at https://www.gov.uk/ government/statistics/national-diet-and-nutrition-surveyresults-from-years-1-to-4-combined-of-the-rolling-programmefor-2008-and-2009-to-2011-and-2012

16. Bates B, Lennox A, Prentice A et al. (2014) Appendix R: Main and Subsidiary Food Groups and Disaggregation Categories. National Diet and Nutrition Survey Years 1-4 (2008/09-2011/12). London: Public Health England; available at https://www.gov.uk/government/statistics/nationaldiet-and-nutrition-survey-results-from-years-1-to-4-combinedof-the-rolling-programme-for-2008-and-2009-to-2011-and-2012

17. Kellet E, Smith A \& Schmerlaib Y (1998) The Australian Guide to Healthy Eating: Background Information for Consumers. Canberra: Commonwealth Department of Health and Family Services; available at http://www.health. gov.au/internet/main/publishing.nsf/content/E384CFA588 B74377CA256F190004059B/\$File/fd-cons.pdf

18. Rangan AM, Randall D, Hector DJ et al. (2008) Consumption of 'extra' foods by Australian children: types, quantities and contribution to energy and nutrient intakes. Eur J Clin Nutr 62, 356-364.
19. Cole TJ, Bellizzi MC, Flegal KM et al. (2000) Establishing a standard definition for child overweight and obesity worldwide: international survey. BMJ 320, 1240-1243.

20. Wijlaars LPMM, Johnson L, van Jaarsveld CHM et al. (2011) Socioeconomic status and weight gain in early infancy. Int J Obes (Lond) 35, 963-970.

21. Rabe-Hesketh S \& Skrondal A (2012) Multilevel and Longitudinal Modelling Using Stata. vol. I: Continuous Responses, 3rd ed. College Station, TX: Stata Press.

22. Mendez MA, Popkin BM, Buckland G et al. (2011) Alternative methods of accounting for underreporting and overreporting when measuring dietary intake-obesity relations. Am J Epidemiol 173, 448-458.

23. Rennie KL, Coward A \& Jebb SA (2007) Estimating underreporting of energy intake in dietary surveys using an individualised method. Br J Nutr 97, 1169-1176.

24. Johnson L, van Jaarsveld CHM \& Wardle J (2010) Individual and family environment correlates differ for consumption of core and non-core foods in children. Br J Nutr 105, 950-959.

25. McGowan L, Croker H, Wardle J et al. (2012) Environmental and individual determinants of core and non-core food and drink intake in preschool-aged children in the United Kingdom. Eur J Clin Nutr 66, 322-328.

26. Woodruff SJ, Hanning RM \& McGoldrick K (2010) The influence of physical and social contexts of eating on lunchtime food intake among Southern Ontario, Canada, middle school students. J Sch Health 80, 421-428.

27. Zoumas-Morse C, Rock CL, Sobo EJ et al. (2001) Children's patterns of macronutrient intake and associations with restaurant and home eating. J Am Diet Assoc 101, 923-925.

28. Zarnowiecki DM, Parletta N \& Dollman J (2016) Socioeconomic position as a moderator of 9-13-year-old children's non-core food intake. Public Health Nutr 19, 55-70.

29. Adams J, Mytton O, White $M$ et al. (2016) Why are some population interventions for diet and obesity more equitable and effective than others? The role of individual agency. PLoS Med 13, e1001990.

30. Rydell SA, Harnack LJ, Oakes JM et al. (2008) Why eat at fast-food restaurants: reported reasons among frequent consumers. J Am Diet Assoc 108, 2066-2070.

31. Lachat C, Nago E, Verstraeten R et al. (2012) Eating out of home and its association with dietary intake: a systematic review of the evidence. Obes Rev 13, 329-346.

32. Church S (2008) Trends in Portion Sizes in the UK - A Preliminary Review of Published Information. London: Food Standards Agency; available at http://citeseerx.ist.psu. edu/viewdoc/download?doi=10.1.1.397.8604\&rep=rep1\&type= pdf

33. Anzman-Frasca S, Dawes F, Sliwa S et al. (2014) Healthier side dishes at restaurants: an analysis of children's perspectives, menu content, and energy impacts. Int J Behav Nutr Phys Act 11, 81.

34. Grieger JA, Wycherley TP, Johnson BJ et al. (2016) Discrete strategies to reduce intake of discretionary food choices: a scoping review. Int J Behav Nutr Phys Act 13, 57.

35. Ebbeling CB, Feldman HA, Osganian SK et al. (2006) Effects of decreasing sugar-sweetened beverage consumption on body weight in adolescents: a randomized, controlled pilot study. Pediatrics 117, 673-680.

36. Ebbeling CB, Garcia-Lago E, Leidig MM et al. (2007) Altering portion sizes and eating rate to attenuate gorging during a fast food meal: effects on energy intake. Pediatrics 119, 869-875.

37. Department for Education (2016) School Food in England: Departmental Advice for Governing Boards. London: Department for Education; available at https://assets.pub lishing.service.gov.uk/government/uploads/system/uploads/ attachment_data/file/551813/School_food_in_England.pdf 
38. Nicholas J, Wood L, Harper C et al. (2013) The impact of the food-based and nutrient-based standards on lunchtime food and drink provision and consumption in secondary schools in England. Public Health Nutr 16, 1052-1065.

39. Evans CEL, Cleghorn CL, Greenwood DC et al. (2010) A comparison of British school meals and packed lunches from 1990 to 2007: meta-analysis by lunch type. Br J Nutr 104, 474-487.

40. Stevens L, Nicholas J, Wood L et al. (2013) School lunches $v$. packed lunches: a comparison of secondary schools in England following the introduction of compulsory school food standards. Public Health Nutr 16, 1037-1042.

41. Macdiarmid JI, Wills WJ, Masson LF et al. (2015) Food and drink purchasing habits out of school at lunchtime: a national survey of secondary school pupils in Scotland. Int J Behav Nutr Phys Act 12, 98.

42. Smith D, Cummins S, Clark C et al. (2013) Does the local food environment around schools affect diet? Longitudinal associations in adolescents attending secondary schools in East London. BMC Public Health 13, 70.

43. de Castro JM (1994) Family and friends produce greater social facilitation of food intake than other companions. Physiol Behav 56, 445-455.

44. de Castro JM (1995) Social facilitation of food intake in humans. Appetite 24, 260.

45. Salvy S-J, Jarrin D, Paluch R et al. (2007) Effects of social influence on eating in couples, friends and strangers. Appetite 49, 92-99.
46. McGuffin LE, Price RK, McCaffrey TA et al. (2015) Parent and child perspectives on family out-of-home eating: a qualitative analysis. Public Health Nutr 18, 100-111.

47. Tyrrell RL, Greenhalgh F, Hodgson S et al. (2016) Food environments of young people: linking individual behaviour to environmental context. J Public Health 39, 95-104.

48. Poti JM \& Popkin BM (2011) Trends in energy intake among US children by eating location and food source, 1977-2006. J Am Diet Assoc 111, 1156-1164.

49. Thompson FE \& Subar AF (2013) Dietary assessment methodology. In Nutrition in the Prevention and Treatment of Disease, 3rd ed., pp. 5-46 [AM Coulston, CJ Boushey and MG Ferruzzi, editors]. Waltham, MA: Academic Press/ Elsevier.

50. Tooze JA, Freedman LS, Carroll RJ et al. (2016) The impact of stratification by implausible energy reporting status on estimates of diet-health relationships. Biom $J$ 58, $1538-1551$.

51. Willett WC (editor) (2013) Nature of variation in diet. In Nutritional Epidemiology, 3rd ed., pp. 34-48. New York: Oxford University Press.

52. Penney TL, Jones NRV, Adams J et al. (2017) Utilization of away-from-home food establishments, Dietary Approaches to Stop Hypertension dietary pattern, and obesity. Am J Prev Med 53, e155-e163. 